\title{
Relatos e reflexóes sobre a Atenção Primária à Saúde em assentamentos da Reforma Agrária
}

\author{
I 1 Ana Carolina de M. T. V. Dantas, ${ }^{2}$ Petrônio José de Lima Martelli, \\ ${ }^{3}$ Paulette Cavalcanti de Albuquerque, ${ }^{4}$ Ronice Maria Pereira Franco de Sá I
}

Resumo: Este estudo de caso objetivou analisar o cuidado à saúde de famílias assentadas no interior do Estado de Pernambuco, mediante observação participante, entrevistas individuais com profissionais de saúde e representante do Movimento dos Trabalhadores Rurais Sem Terra - MST, grupos focais com as famílias de dois assentamentos e diário de campo. Observou-se que as práticas de saúde estavam relacionadas ao cuidado popular por meio do uso de plantas medicinais, ações de prevenção, como vacinação, puericultura, acompanhamento a hipertensos e diabéticos, tratamento da água e destino do lixo. Identificou-se que fatores socioeconômicos, culturais e educacionais impactavam, de maneira negativa, na condição de saúde, enquanto a formação dos profissionais e a capacidade resolutiva da Atenção Primária limitavam a oferta de açóes. Apesar de as práticas de saúde estarem de acordo com a Política Nacional da Atenção Básica, havia lacunas entre o fazer saúde técnico e o fazer saúde popular. Destacaram-se as ações realizadas pelo Movimento, como o diagnóstico da condição de saúde e planejamento, a partir da educação popular. As necessidades de saúde apresentadas pelas famílias demandavam das equipes competências e habilidades específicas para o cuidado à saúde integral implicado com a realidade socioeconômica, cultural e sanitária dos assentamentos da Reforma Agrária.

> Palavras-chave: política de saúde; atenção básica; Saúde da Família; saúde rural.

\author{
1 Universidade Federal de \\ Pernambuco. Recife-PE, Brasil \\ (caroldantas.to@gmail.com). \\ ORCID: 0000-0001-8499-9429 \\ ${ }^{2}$ Universidade Federal de \\ Pernambuco. Recife-PE, Brasil \\ (petroniocarla@uol.com.br). \\ ORCID: 0000-0001-6920-6435 \\ ${ }^{3}$ Centro de Pesquisas Aggeu \\ Magalhães. Recife-PE, Brasil \\ (paulette.cavalcanti@gmail.com). \\ ORCID: 0000-0001-8283-5041 \\ ${ }^{4}$ Universidade Federal de \\ Pernambuco. Recife-PE, Brasil \\ (ronicefranco@gmail.com). \\ ORCID: 0000-0003-4943-710X
}

Recebido em: 27/02/2018 Revisado em: 20/02/2019 Aprovado em: 28/02/2019 


\section{Uma aproximação com a saúde dos povos do campo}

Um breve resgate acerca da Questão Agrária e Luta pela Terra no Brasil permite constatar que, desde a chegada da Corte portuguesa em território nacional, século XVI, há disputa pela posse, uso e propriedade da terra. Os elementos estruturantes do modelo fundiário, que se instaurou no período colonial, perpetuaramse mediante a concentração de terra, incentivo à monocultura e agricultura exportadora, manutenção dos latifúndios como espaços improdutivos, exploração dos/as trabalhadores/as camponeses/as, favorecimento do agronegócio, entre outros (MST, 2014; STEDILE, 2012).

A constituição dos povos do campo foi acompanhada pela formação de movimentos sociais nas distintas regióes do país que resistiram e continuam resistindo contra os processos de exploração, expropriação e expulsão em seus territórios, reivindicando o direito de viver e produzir na terra, com condiçôes sociais necessárias à vida digna (MST, 2014; FERNANDES, 2008).

Em períodos de intensificação das contradiçôes existentes no modelo agrário, os movimentos de resistência do campo estiveram mais combativos e resistentes, como observado no final da década de 1970. Nessa fase, as ocupaçôes de terra começam a reaparecer como ferramenta de expressão, contestaçáo e resistência dos povos do campo contra o autoritarismo e a ofensiva do Estado e latifundiários (MST, 2014).

Dentre esses movimentos oriundos da luta pela terra na década de 1980, destaca-se o Movimento dos Trabalhadores Rurais Sem Terra (MST). Em 35 anos de trajetória, o MST vem dialogando com os diversos movimentos sociais, que lutam por um projeto de sociedade com o intuito de atender aos anseios da classe trabalhadora do campo e da cidade. Isso vem exigindo a ampliação permanente das frentes de atuação do Movimento, que, além de inserir os interesses particulares dos grupos ou pessoas, constrói estratégias para garantir a Reforma Agrária em todo o país (CALDART, 2012).

O modo de atuação do Movimento está baseado no uso de ferramentas pedagógicas voltadas à formação política, práticas que tensionam o Estado, como as marchas, o povo na rua, trancamento de rodovias, atos políticos, ocupações de terra, entre outras. Esta última é uma das mais expressivas e contribui fortemente para a construção da identidade Sem Terra, cuja tarefa principal é ocupar. Nessa condição, as famílias acampadas se mantêm mobilizadas por meio da auto-organização em 
setores, funcionando articulados entre si para garantir a permanência no latifúndio ocupado (CALDART, 2012).

Resistir é o segundo desafio. São criados os Núcleos de Base (saúde, educação, comunicação, produção), que viabilizam a continuidade da formaçáo política indispensável à permanência organizada do acampamento. A meta dessa etapa é conseguir a desapropriação para fins da Reforma Agrária, ou seja, que para as famílias ali acampadas seja concedida a posse da terra, tornando-as assentadas (CALDART, 2012).

$\mathrm{Na}$ condição de assentamento, torna-se possível, de maneira menos instável e conflituosa, exercer a terceira tarefa coletiva de produzir outras relaçóes sociais, econômicas e políticas a partir daquele espaço. Porém, sabe-se que os latifúndios desapropriados para assentamentos normalmente possuem poucas benfeitorias e infraestrutura, como saneamento, energia elétrica, acesso à cultura e lazer (MST, 2014).

Segundo dados disponibilizados pelo Instituto Nacional de Colonizaçáo e Reforma Agrária (INCRA), em fevereiro de 2017, existiam no Brasil 9.354 assentamentos com 975.985 famílias assentadas. Destas, 34.207 se distribuem em 613 assentamentos no Estado de Pernambuco, que ocupa o $4^{\circ}$ lugar entre os estados com maior número de assentamentos da Reforma Agrária, ficando atrás dos estados do Pará, Maranhão e Bahia. Do total de assentamentos, oito se encontram no município de Caruaru, na regiáo do agreste pernambucano, onde habitam 218 famílias (INCRA, 2017).

As populaçôes do campo, da floresta e das águas, residentes, em sua grande maioria, nas regiốes do Norte e Nordeste do país, encontram-se em situaçôes de iniquidades, vulnerabilidade e desigualdades históricas e estruturais, ainda mais graves quando comparadas à população urbana. No século XXI, as populações mais invisíveis para as políticas públicas do Estado são os/as camponeses/as, populaçôes atingidas por barragens, extrativistas, pescadores, ribeirinhos, quilombolas, indígenas, dentre outras (CARNEIRO et al., 2014).

Muitas barreiras já foram vencidas e houve melhorias com relação à condição de saúde da população a partir da expansão da Atenção Primária à Saúde (APS). No entanto, ainda se identificam desigualdades de acesso, baixa resolutividade das açôes de saúde e descontinuidade do cuidado, associada à elevada concentração de profissionais nos espaços urbanos, tendo em vista a diversidade sociocultural e ambiental existente em todo o território brasileiro (GARNELO, et al., 2018). 
Foi somente em 2 de dezembro de 2011, o Ministério da Saúde instituiu oficialmente a Política Nacional de Saúde Integral da População do Campo, da Floresta e das Águas (PNSIPCFA) mediante Portaria no 2.866/GM/MS. Essa política se estrutura em quatro eixos estratégicos, e, no que se refere ao acesso das populaçóes do campo e da floresta na atenção à saúde, encontra-se o direcionamento para ampliação da Atenção Básica (AB) (BRASIL, 2013).

Com essa base conceitual, este estudo de caso (YIN, 2001) com abordagem prioritária qualitativa teve por objetivo analisar o cuidado à saúde de famílias que vivem em assentamentos da Reforma Agrária em Pernambuco. Dessa forma, os resultados apresentados neste artigo são provenientes da investigação sobre contexto socioeconômico e cultural dos territórios, das práticas de saúde vivenciadas pelas equipes da APS, Setor Saúde do MST - PE e famílias assentadas, considerando os desafios e as potencialidades nesse âmbito da atenção à saúde.

\section{Andar, ver e escrever: ferramentas e trajetórias metodológicas}

Segundo Yin (2001), o estudo de caso representa uma investigação empírica em torno de um fenômeno contemporâneo dentro de seu contexto da vida real. Tratase de uma estratégia para examinar acontecimentos em que o pesquisador não tem controle sobre os eventos comportamentais, sejam eles no âmbito individual, organizacional, social ou político. Enquanto método, possibilita abranger a multiplicidade de dimensóes de um problema e analisar, em profundidade, os processos e as relaçóes entre eles, por se basear em várias fontes de evidências (VENTURA, 2007).

Para tanto, foi utilizada a observação participante durante os atendimentos na Unidade de Saúde da Família (USF) - Lajes, visitas domiciliares, atendimentos nos pontos de apoio em comunidades mais distantes da USF, sala de espera; entrevistas individuais com os profissionais das equipes de saúde e setor saúde do MST - PE; grupos focais em dois assentamentos da Reforma Agrária: Macambira/Borba e Lago Azul; e registros em diário de campo.

Tanto a USF quanto os assentamentos foram selecionados para a pesquisa, uma vez que estavam sendo campo de prática da equipe de RMSF Campo, da qual a pesquisadora participava como tutora e, por isso, acompanhava as vivências e questóes em torno desses territórios. 
A USF de Lajes pertence ao $2^{\circ}$ Distrito de Caruaru, com a comunidade adscrita distribuída em cinco microáreas, estando uma descoberta por Agente Comunitário de Saúde (ACS). Essa USF é uma das 18 localizadas em área rural do total de 63 USF, em todo o município de Caruaru, que apresenta cobertura populacional de Equipe de Saúde da Família (eSF), estimada em 69,26\%, segundo dados do Departamento de Atenção Básica (BRASIL, 2017a). A equipe que atua na unidade é composta por uma médica, um enfermeiro, quatro ACS, uma cirurgiā-dentista, uma técnica de saúde bucal, uma técnica de enfermagem, uma prestadora de serviços gerais, dispondo de uma equipe multiprofissional vinculada à Residência Multiprofissional em Saúde da Família, com ênfase na população do Campo (RMSF Campo), também oferece assistência às famílias adscritas e apoio à equipe de referência.

Esses profissionais davam cobertura a, aproximadamente, 1.000 famílias, cerca de 4.000 pessoas, número que ultrapassava a média recomendada pela Política Nacional de Atenção Básica - PNAB (BRASIL, 2017), que é de 2.000 a 3.500 pessoas por equipe. Esse fator se mostrava mais significativo, por se tratar de um território rural, onde a dispersão geográfica requeria maior tempo para deslocamento das equipes da USF até as famílias, e vice-versa. Destaca-se que a PNAB (2017) prevê outros arranjos de adscrição, conforme vulnerabilidades, riscos e dinâmica comunitária, podendo ser maiores ou menores do que o parâmetro recomendado, de acordo com as especificidades do território, assegurando-se a qualidade do cuidado (BRASIL, 2017).

Foram entrevistados individualmente seis profissionais de saúde, sendo três da Equipe de Saúde da Família (eSF) e três da equipe do Núcleo de Apoio à Saúde da Família da Residência Multiprofissional em Saúde do Campo (eNASFR), um representante do setor saúde do MST-PE e dez assentadas/os em dois grupos focais nos assentamentos de Macambira/Borba e Lago Azul, totalizando 17 sujeitos identificados a partir de nomes de plantas típicas da região.

A pesquisa cumpriu com as exigências da Resolução CNS 466/12 e foi aprovada pelo Comitê de Ética em Pesquisa do Centro de Ciências da Saúde CCS da Universidade Federal de Pernambuco - UFPE, com o número de CAAE: 58398016.4.0000.5208, tendo os participantes aderido voluntariamente, mediante assinatura do Termo de Consentimento Livre e Esclarecido - TCLE. 
A análise do material ocorreu sob a ótica descritiva e interpretativa com base na identificação das temáticas prevalentes, busca de significados, convergências e divergências do fenômeno em questão. As demais etapas obedeceram à seguinte ordem: a) leitura panorâmica; b) releitura para identificação dos conteúdos que se relacionavam ao objeto de estudo; c) definição das categorias a partir do agrupamento dos conteúdos correlacionados na segunda etapa; d) diálogo das categorias com o referencial teórico. Após a análise, surgiram três eixos para discussão: 1) a organicidade e o contexto socioeconômico e cultural das famílias assentadas; 2) as práticas de saúde e a necessidade de ampliar o pensar e fazer saúde em assentamentos da Reforma Agrária; 3) desafios e potencialidades da saúde do campo.

\section{Ocupar e resistir: a organicidade e o contexto socioeconômico e cultural das famílias assentadas}

Depois de assentadas, as famílias devem permanecer organizadas no MST, pois a conquista da terra é apenas o primeiro passo para a realização da Reforma Agrária. Como aponta Roseli Caldart (2012), a luta é duradoura e tem como base duas liçóes aprendidas ao longo do tempo: a primeira afirma que a luta não acaba com a conquista da terra, e a segunda, que a luta também não termina enquanto existirem famílias sem-terra.

No entanto, o que se observa, de maneira geral, é a dificuldade de manter as famílias organizadas com sentimento de pertencimento ao Movimento após a conquista da terra. O formato dos assentamentos em parcelas, muitas vezes distantes umas das outras, dificulta a convivência entre as famílias assentadas, o que desfavorece a organização:

Eu ainda sinto falta de acampamento, sabia? Apesar das dificuldades, mas tem hora que eu sinto falta [sente falta de quê?] Da união maior porque tem união bem maior quando é acampamento [...] depois que cada um foi para os seus cantos, aí muda muito. Eu acho que em minha opinião é porque depois que passa a ser assentamento, aí passa a ser cada um por si, né? Enquanto é acampamento, aí tá se lutando tudo junto por uma causa só, né, aí depois não, depois você ganha sua parcela aí vai cuidar para lá da sua eu já tô aqui na minha vou cuidar da minha, eu acho que é por aí sei lá entendeu (Xique-xique).

Percebe-se que a configuração de acampamento permite maior interação e organização coletiva em torno da luta pela garantia de direitos sociais, além da conquista da terra. Por outro lado, o formato - inclusive territorial - dos 
assentamentos gera afastamento entre as famílias e consequente desmobilização, perdendo a característica de continuidade da luta, como propóe o Movimento desde a sua origem, diluindo princípios, como a organicidade, coletividade e solidariedade, segundo a fala de uma das assentadas: "Quando é acampamento sei lá... é tâo diferente! É uma preocupaçâo tão grande um com o outro; depois que virou assentamento é cada um na sua casa é cada um por si” (Xique-xique).

$\mathrm{Na}$ contramão dessa tendência, o setor saúde do MST-PE vem desenvolvendo atividades de fomento à reorganização dessas famílias, pautadas na educação popular. Visa ao resgate da organicidade interna, orientada à prática e vinculada a uma análise mais ampla da questão de saúde por meio do incentivo e da construção da autonomia transformada em luta. Pois, "toda conquista parte da luta, e eles são sujeitos desse processo, eles são protagonistas, e não se deve esperar só do outro que vem de fora. Mas, entender que eles são parte da comunidade, de como eles conseguem fazer uma leitura de saúde" (Mandacaru). Aponta, então, para a necessidade de incluir as famílias assentadas no planejamento das atividades junto com as equipes da APS.

Semelhante à realidade de outros assentamentos rurais, a estrutura de equipamentos sociais é precária, o que expressa, mais uma vez, a negação dos direitos sociais às famílias assentadas por parte do Estado. Pois constata-se a ausência de escolas, espaços de lazer e convivência, falta de iluminação e segurança pública, dificuldade com transporte, rede de saneamento básico insuficiente, trabalho e renda precarizados. Assim, as crianças, os adolescentes e adultos que precisam estudar têm de se deslocar a pé ou utilizando ônibus escolar que transita pela BR 104, para chegarem até a área mais urbanizada de Lajes, onde existe uma escola com Ensino Fundamental I. A fim de dar continuidade aos estudos do Ensino Fundamental II e do Ensino Médio, precisam se deslocar para Toritama (cerca de $15 \mathrm{~km}$ ), até a comunidade do Rafael, Cachoeira Seca ou, ainda, para a zona urbana de Caruaru (cerca de $20 \mathrm{~km}$ ).

Dentre as necessidades apontadas pelas assentadas, está a construção de uma escola no Assentamento:

Aqui também não tem o que deveria ter porque a gente sai daqui para ir para cidade se arriscando de não voltar. De ir e não voltar que tem assaltos, tem tudo por aí, tem muitos que vão e náo voltam. A gente deveria ficar aqui porque como tem na cidade, aqui também deveria ter. Eu tenho uma professora para ir, mas já fica ali na sede não é bem uma escola (Catingueira). 
O questionamento feito ao grupo de mulheres que participaram do grupo focal nesse Assentamento sobre as atividades de lazer, e a existência desses espaços nas proximidades, foi motivo de gargalhadas seguidas da fala de uma delas:

Eita! Chegou a hora do lazer de nós [...] para se divertir é em cima da máquina [de costura] mesmo. É aqui de domingo a domingo [...] Eu saio é para a igreja em Lajes assim no domingo é para onde a gente sai mesmo [...] mas realmente para se divertir eu mesmo nem lembro da época que eu tenha saído. Tem não! nem para as crianças nem para nada (Jurema).

Tendo em vista a importância dos espaços de lazer e convivência para a qualidade de vida, o que se observou foi a existência de bares e campos de futebol que são frequentados, em sua maioria, por homens. Resta às mulheres frequentar as instituiçóes religiosas como alternativa à socialização, em especial da vertente protestante.

\section{Produzir: as práticas de saúde e a necessidade de ampliar o pensar e fazer saúde em assentamentos da Reforma Agrária}

As ações de saúde de caráter comunitário e preventivo junto com a população de áreas rurais ou periféricas tiveram, inicialmente, como objetivo reduzir o quadro de epidemias que assolavam esses grupos ou, ainda, ofertar o mínimo de cuidado à saúde, considerando o fato de não haver, sequer, o profissional médico em regiôes remotas do país. Sem dúvida, o perfil dessas açóes foi se reconfigurando ao longo dos anos, principalmente a partir do compromisso constitucional assumido em referência à efetivação do SUS.

Com base na análise das práticas de saúde nos assentamentos, foi elaborado um fluxograma (figura 1) dos elementos que interferiam na configuração da Saúde da Família daquelas áreas. Esses pontos dialogavam entre si, dando contorno ao modo de pensar e fazer saúde do Campo, de acordo com os sujeitos que compartilham esse território. 
Figura 1. Conexôes temáticas da Saúde do Campo

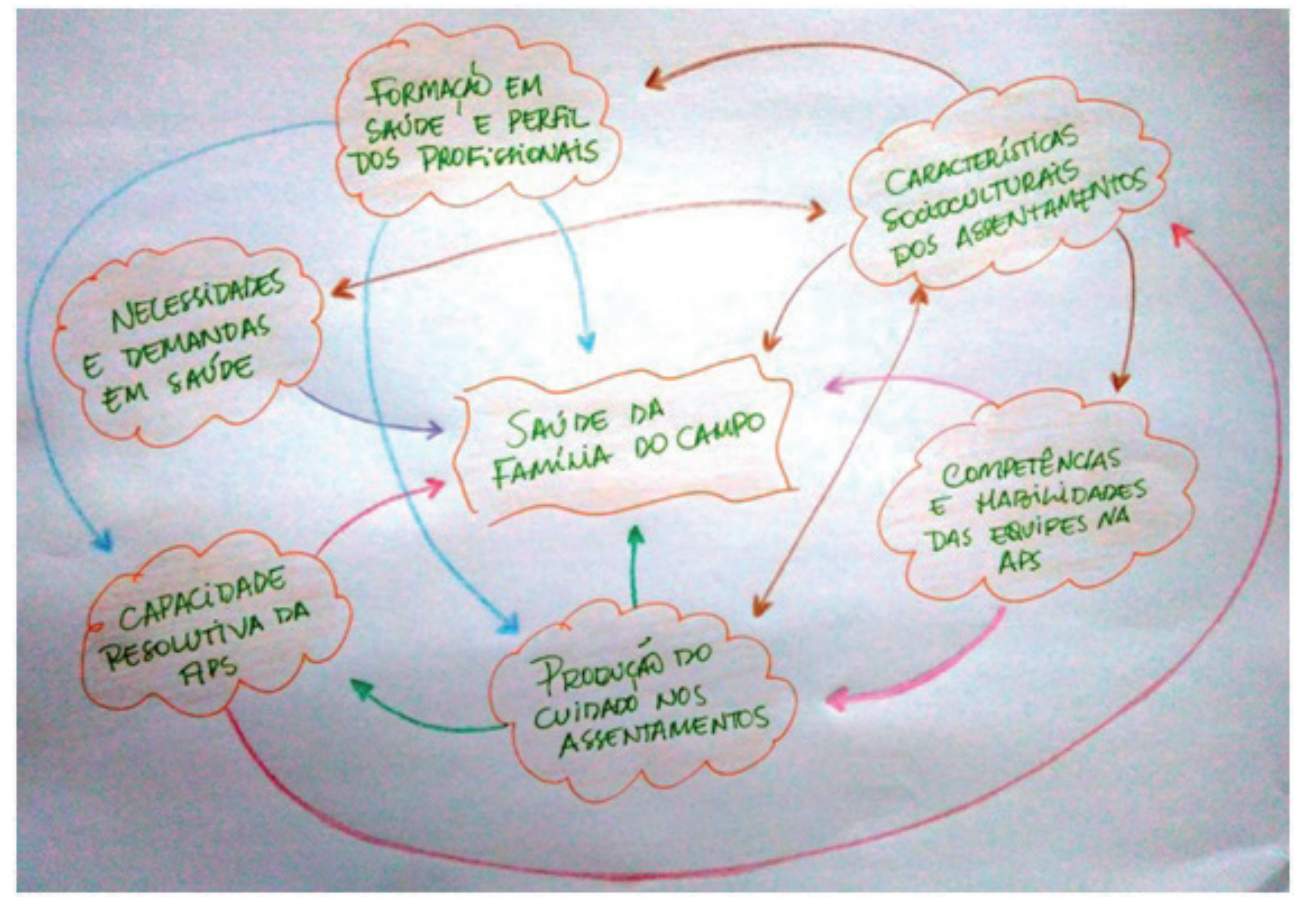

O cuidado na lógica da clínica ampliada, o planejamento com base nos modos de vida das famílias, a gestão compartilhada e o investimento em educação permanente das equipes também foram destacados como fatores relevantes para a garantia de efetividade das práticas de saúde na APS.

Sobre esse aspecto, o funcionamento da USF-Lajes acontece mediante o cumprimento de uma agenda fixa semanal planejada, segundo os profissionais da equipe de referência, de acordo com a demanda das comunidades adscritas.

Bom, isso, a gente tá na fase de engatinhar ainda, né? Porque de 3 anos para cá aqui começou a ver essa questão realmente de planejamento baseado nas necessidades da comunidade. a gente faz essa rotatividade porque antes náo existia nenhum tipo de planejamento, a gente não tinha realmente açóes voltadas às situaçôes específicas da comunidade e hoje a gente consegue fazer através das reuniôes (Umbuzeiro).

A instituição de reuniôes para planejamento das atividades, discussão de casos, construção de Projeto Terapêutico Singular (PTS) ainda representa um nó dentro do processo de trabalho das equipes da APS e exige reorganização do cotidiano do serviço. 
Segundo as assentadas entrevistadas, não há atividades de planejamento conjunto com a eSF. O comentário da Assentada de Lago Azul, quando se referiu à retirada das vagas específicas para o atendimento odontológico na USF, ilustra a situação:

Eles fazem as reuniões e definem as coisas e nós não fica sabendo [...] lá no posto eles fazem reunião, define e você quando chega lá fica sabendo. Já sabe que mudou, já fica sabendo que não tem mais disponibilidade porque mudaram e não procuraram atendimento e as vagas foram disponibilizadas para os outros e nós os que necessitam ficam sem aí é complicado (Jurema).

Sobre esse aspecto, as açóes na APS devem responder às necessidades de saúde da população, com a priorização de intervenções clínicas e sanitárias, segundo critérios de frequência, risco, vulnerabilidade e resiliência. Inclui-se aqui o planejamento e a organizaçáo da agenda de trabalho compartilhado de todos os profissionais e "recomenda-se evitar a divisão de agenda, segundo critérios de problemas de saúde, ciclos de vida, sexo e patologias, dificultando o acesso dos usuários" (BRASIL, 2017, p. 43).

As equipes identificavam os fatores socioeconômicos e culturais como estruturantes das condiçôes de saúde, devendo ser considerados no planejamento das açôes, como era o caso do trabalho nos fabricos, ${ }^{1}$ que dificultava a participação das pessoas nas atividades da USF. No entanto, as práticas tinham um perfil curativista, biomédico e individual centradas no atendimento na USF, apesar do reconhecimento de que "existem questóes que extrapolam aquilo que eles fazem na unidade" (Mulungu).

O modelo fica igual [ao da cidade], entendeu? De HiperDia, aquele modelo de vacina, puericultura e as pessoas que tem que ir independente se mora a 20 quilômetros ou se mora a dois quilômetros tem que chegar na unidade [...] fica mais nas ações curativas (Cacto).

Eu tenho tentado fazer mais ação de prevenção de doença cardiovascular, prevenção de complicaçôes cardiovascular de hipertenso e diabético, algumas educativas também como as que eu tenho que fazer com a nutricionista para dizer para as máes como alimentar as crianças [...] individuais são mais as abordagens durante as consultas mesmo quando eu tento ver o paciente dos pés à cabeça (Caroá).

$\mathrm{O}$ cuidado ofertado pela equipe de referência está mais relacionado à clínica médica, que, de acordo com os profissionais da USF, é a maior demanda da população adscrita, sendo reservado um dia por semana para atender a essa necessidade. Desenvolvem ações preconizadas pela política nacional, como atenção aos hipertensos e diabéticos, puericultura e pré-natal, pediatria, planejamento familiar, 
renovação de receitas, programa vacinal, consultas odontológicas, entre outras. No período da pesquisa, parte da eSF também estava participando de uma atividade de educação permanente em Saúde Mental, oferecida pela gestão municipal, por ser uma demanda recorrente das equipes da APS.

Identificou-se, ainda, que a compreensão acerca do processo saúde-adoecimento e o perfil da intervenção variavam entre as diferentes categorias profissionais. A atuação da ACS tinha um caráter mais preventivo com ações de educação em saúde, orientaçóes sobre uso adequado da água, abordagens sobre os focos de lixo nas comunidades, entre outras que apresentaram maior aproximação com o contexto de vida das famílias.

No caso dos profissionais da eNASFR, as práticas de saúde são planejadas a partir do processo de territorialização e diagnóstico, que realizam ao ingressarem no programa de residência. Esse fato diferencia a intervenção deles no sentido de serem mais voltadas à promoção da saúde, organização/mobilização da comunidade, açôes de geração de renda, articulação com a rede de atenção à saúde e intersetorialidade, incentivo ao uso de plantas medicinais e fortalecimento do saber popular.

Destaca-se a formação de grupos de mulheres, saúde mental e qualidade de vida; atendimentos individuais, porém, buscam priorizar as açóes coletivas, por identificarem "que o próprio território vai convidando a gente a pensar de forma coletiva" (Mulungu).

Esse último enfoque das açôes está diretamente relacionado aos relatos das famílias assentadas sobre como cuidam da saúde:

Quando é uma dor de barriga a gente faz um chá de erva cidreira, chá de boldo, quando é
com diarreia gente faz um soro caseiro. Quando vê que não tem jeito mesmo aí é preciso
levar para Toritama. Leva direto para Toritama. Esse posto aí mesmo eu só vou quando
é pra dar uma vacina. Eu cuido por aqui mesmo em casa mesmo quando eu vejo que a
medicação que eu tô fazendo em casa assim, o soro caseiro, um chazinho de erva doce,
de erva cidreira não tá servindo aí eu levo pro hospital de Toritama. Quando eu tô com
dinheiro para ir para UPA eu vou para UPA em Caruaru aí quando não tem quando não
dá para ir de jeito nenhum, um canto que eu vou mais barato é para Toritama porque é
mais barato é mais perto né aí a passagem se torna mais barata [...] de vez em quando tem
uma gripezinha aí nós faz um lambedor em casa (Palma).

Foi frequente esse tipo de relato entre as famílias assentadas, que recorrem, muitas vezes, aos serviços de saúde no município de Toritama (município vizinho), por ser menos oneroso o deslocamento. Essa escolha também está relacionada à dificuldade 
em realizar consultas, marcaçôes de exames e obter atendimento de urgências na USF-Lajes, que, de acordo com as/os assentadas/os, supre demandas, como vacinação, aquisição de medicamentos, acompanhamento às crianças, hipertensos e diabéticos.

De acordo com relatos dos setores estaduais de saúde do MST (2005), as experiências do Movimento referem-se, principalmente, à convivência e ao cuidado entre militantes e familiares em caso de adoecimento, à promoção de hábitos saudáveis, à efetivação do direito à saúde, ao preparo de remédios à base de plantas medicinais, ao cuidado com alimentação, com a higiene e com o ambiente, entre outras.

Com o objetivo de fomentar a autonomia e o protagonismo das famílias no processo de cuidado à saúde, o coletivo de saúde do MST-PE tem realizado diagnóstico de saúde nos acampamentos e assentamentos. Este coletivo também tem atuado por meio de minisseminários, reuniōes de diagnósticos, planejamentos e avaliação das atividades e a necessidade de sensibilizar os profissionais da Saúde da Família quanto às especificidades do campo. Não houve relato, porém, de atividade junto com as equipes, a fim de enfrentar esse entrave, apesar de vir contribuindo diretamente na coordenação e no desenvolvimento da RMSFCampo em parceria com a UPE e o coletivo Gráo de saúde do campo.

Por outro lado, identificam-se entraves de diversas ordens que fragilizam a estruturação de serviços de saúde acessíveis, universais e equânimes. Córdova, Ribas e Wosny (2011), ao estudar a realidade de saúde de assentados, afirmam que as principais dificuldades quanto ao acesso aos serviços da APS se referem a distância, ao desconhecimento por parte dos gestores e profissionais sobre a realidade do assentamento, à falta de ACS da comunidade, funcionando a USF como um quebragalho, seguindo os mesmos programas propostos para a área urbana.

A produção de práticas de saúde integrais no contexto de assentamento da Reforma Agrária requer formação profissional mais humanizada, solidária, popular e voltada ao trabalho interprofissional e intersetorial, no qual o campo de aprendizado seja composto pelos territórios vivos com todas as suas fragilidades e potências. Esses esforços vêm acontecendo na instituição de novos currículos para graduação e nas estratégias de educação permanente, como é o caso dos programas de residências multiprofissionais em saúde da família, saúde mental e, recentemente, em saúde do campo.

As práticas vêm sendo ampliadas com a inserção das equipes multiprofissionais por meio da RMSFCampo, pois os profissionais reconhecem que "só conseguem ir 
até certo ponto do nosso conhecimento; então foi aí que eu precisei do pessoal da educação física, o pessoal da Nutrição, da Terapia Ocupacional” (Caroá) e analisam que as intervenções junto com as populaçôes do campo "extrapolam o meu núcleo, sabe? Eu preciso aprender a ler, a fazer outra coisa para lidar com aquilo que tá aparecendo; não dá para ficar só na minha disciplina não, tem que ir lançar mão de outras estratégias" (Mulungu). Como também reforça outra profissional:

Por aqui é muita coisa e coisas que não tem como dar uma resolutividade, entendeu? Isso é o mais difícil. Depois de estudar 5 anos na academia e ver que tipo nada do que você estudou vai vale servir muito não, viu? Há outras coisas que você tem que desenvolver, outras coisas que você tem que criar, outras coisas que você tem que fazer (Cacto).

Desse modo, retomamos os apontamentos da Sociedade Brasileira de Medicina de Família e Comunidade (NANDO et al., 2011) com relação ao manejo dos problemas de saúde nas áreas rurais, que, geralmente, requerem tempo e ritmos diferenciados, como no caso de emergências que necessitam de estabilização inicial antes do transporte para outros pontos do sistema de saúde; a necessidade de haver uma ampliação da escala de habilidades para uma abordagem integral e sociofamiliar, incluindo competência dialógica intercultural; considerando ainda que o profissional de saúde rural costuma agir mais em situaçôes de relativo isolamento ou com equipes menores e recursos restritos.

\section{Desafios e potencialidades da saúde do campo: a APS como terra fértil para integralidade do cuidado}

Nessa sessão, trataremos de desafios e potencialidades trazidos por aquelas/es que vivenciam diariamente essa realidade. Em nossa análise, esses aspectos servem de pontos para reflexão às equipes de saúde da APS, famílias assentadas e MST-PE, a fim de construírem canais de diálogo e prática entre ambos.

As demandas no contexto de vida das famílias assentadas extrapolam a atuação na APS preconizada nacionalmente, bem como a abordagem de saúde centrada nos fatores biológicos, uma vez que envolve a carência por serviços públicos que tornam mais evidentes a interferência de fatores sociais, econômicos, culturais e educacionais, incidindo na condição saúde-adoecimento. Assim, foram recorrentes discursos relacionados ao modo de vida no campo, envolvendo moradia, transporte, escola, saneamento básico, trabalho, alimentação, segurança pública e outros aspectos estruturais da determinação da saúde. 
A necessidade de criar novas práticas por meio de ferramentas metodológicas da educação popular com incentivo e valorização dos conhecimentos e das vivências populares apresentou-se como um potencial componente do cuidado nessas comunidades, que extrapola o modo de funcionar da APS preconizado:

A gente tem muitas ferramentas, a gente tem muitos focos, mas aí a gente precisa na
verdade é ampliar as parcerias aumentar e aí o que eu acho primordial seria justamente a
parte da educação (Umbuzeiro).
De potencialidades eu acho que a atenção básica é aquela que tá lá no território, é aquela
que tá lá no dia a dia da populaçáo, entendeu? Então, como essa ausência de serviço é
muito grande dentro do território do campo, a única coisa que existe lá é a saúde e a
escola, né? São os grandes potenciais desses lugares. Então tem muita coisa que pode ser
desenvolvida ali, muita coisa que poderia ser da saúde junto com a educação e desenvolver
aquele território ali para que eles não precisassem sair dali (Cacto).

Destacaram a dificuldade com transporte e locomoção no território como sendo um dos maiores entraves para garantir a efetividade das ações de saúde. Isso inclui as precárias condiçôes das estradas, insegurança, falta de iluminação, transporte público escasso e oneroso para as famílias que precisam se deslocar até a USF, por ser o espaço onde se concentram as atividades oferecidas pela equipe.

Acrescentam-se a esses entraves aqueles aspectos que delineiam o processo de trabalho intra e interequipes, consequentemente, o fazer saúde. Assim, a barreira, por vezes velada, erguida historicamente na formação em saúde para uma visão fragmentada do sujeito, com intervençóes isoladas nos núcleos de saberes, sobretudo por não compreender as necessidades de saúde como uma produção social, mas estritamente biológica e individualizada. Soma-se a isso "o desconhecimento dos profissionais e gestores sobre quem são e como vivem os povos do campo" (Mandacaru).

Starfield (2002) apontou que a acessibilidade, a localização geográfica do serviço, os horários e dias de funcionamento, bem como o processo de utilizaçáo dos serviços por parte da populaçáo são elementos essenciais para que a APS seja considerada a porta de entrada do sistema de saúde. Acrescente-se que, de acordo com Malta et al. (2016), para ser resolutiva, requer a ampliação do acesso às demandas dos usuários, incluindo acolhimento e capacidade para resolver essas demandas espontâneas ou programadas, fato esse que depende, também, da integração com os outros níveis de assistência do sistema de saúde municipal e estadual. Com relação a essa questão, ficaram evidentes as poucas condiçóes de referenciar e contrarreferenciar as/os usuárias/os, pelo fato de haver concentraçáo dos serviços na cidade, embora tenha 
sido descrito como possível e potente o desenvolvimento de açóes de saúde nas escolas, por estas serem os equipamentos sociais disponíveis no território.

Os profissionais são constantemente desafiados a reorganizarem seu processo de trabalho e o serviço, de modo a facilitar o vínculo com as famílias, a fim de garantir a qualidade do cuidado não somente às pessoas que acessam a USF, mas também realizar busca ativa às famílias que não chegam à Unidade por razôes diversas.

Esse desafio é acompanhado por outro, que é a realização de açóes externas à USF com abrangência coletiva nos assentamentos, de promoção da saúde e prevenção de agravos, por demandarem integraçáo de saberes perante um campo de conhecimento comum que não está sendo priorizado, conforme vemos no relato abaixo:

Temos conseguido avançar pouco nas ações coletivas. Eu acho que a gente poderia ter avançado mais $[. .$.$] a gente tá mais no núcleo mesmo familiar; eu mesmo trabalho muito$ mais com as famílias individualmente [...] as açóes individuais ficam muito mais fortalecidas. Construir uma coisa coletiva é mais difícil, entende? É um desafio (Cacto).

Assim, a compreensão ampliada de saúde com a qual os serviços do SUS devem trabalhar se apresenta como carro-chefe para a criação de novos modos de pensar e fazer saúde do Campo. Pois é recorrente o adoecimento relacionado à alta exposição ao sol; acidentes de trabalho e adoecimento em decorrência do modo de produção, seja na agricultura e/ou nos fabricos têxteis; adoecimento e morte por uso de agrotóxico; diarreias e verminoses; e no extremo das necessidades, a fome, que ainda assola a vida de muitas famílias.

A gente tem um desafio que talvez não seja específico de Caruaru, mas que seja a nível nacional e que está relacionado muito a questấo social. A gente volta para questóes de educação [...] educação da comunidade e educação continuada para os profissionais. Quesito social também as condiçôes de vida que boa parte das famílias leva [...] isso é um desafio muito grande (Umbuzeiro).

Eu não consigo olhar para uma comunidade que sofre altos índices de ansiedade e depressão e dissociar da falta de serviço na comunidade, não consigo dissociar disso a questão da miserabilidade das comunidades, da questão educacional, de como falta água para beber e para cozinhar, mas para lavanderia não falta água para lavar o jeans. Como Estado privilegia os pequenos empresários e deixa a comunidade. Então eu não consigo dissociar isso do processo de saúde (Mulungu).

De acordo com a SBMFC (NANDO et al., 2011), em geral, os índices de saúde e de condiçôes sociais em área rural são piores que os urbanos; determinados problemas de saúde são mais frequentes em áreas do campo; as taxas de cobertura preventiva são piores em áreas rurais; e a autoavaliação da saúde também é pior 
nessa população. Assim, as equipes devem ter capacidade de realizar procedimentos diagnósticos e terapêuticos que, emáreas urbanas, comumente seriam encaminhados para outros locais do sistema.

Por que para sociedade eu tô com saúde quando eu não tô com febre quando eu não tô
com dor, não conseguem associar que a falta de terra a falta de náo ter o acesso à política
pública, é um problema de saúde para o ser humano [...] porque na sociedade que a gente
vive hoje o sujeito não tem acesso à casa, moradia, educação, entendeu? Até um trabalho.
Então assim, são as coisas que vão desencadear o processo [de adoecimento] então se você
não consegue trabalhar isso dentro dos espaços que a gente tá, vai sempre gerar dificulda-
de do entendimento do que é saúde. Vai pensar que a saúde é só o acesso ao serviço, é só a
coisinha pontual e que não vai dar resolutividade nenhuma porque se eu dou um remédio
pra dor de cabeça dele resolve hoje, imediata, mas essa dor de cabeça vai vir recorrente
porque o que desencadeia isso nele muitas vezes é a falta do emprego, é a falta do trabalho,
eu não tenho a terra para produzir a sua alimentação (Mandacaru).

Além disso, o aprimoramento da saúde do campo deve estar associado a uma forte orientação da rede municipal para APS, à ampliação da capacidade das equipes em apreender as reais necessidades das comunidades, desconcentração e territorialização dos demais serviços da rede. Nesse sentido, corroboramos Targa et al. (2014), quando afirmam que o cuidado centrado na comunidade com competência cultural deve ser o princípio de todas as políticas de sistema de saúde, sobretudo no que concerne à atenção às populaçôes do campo e suas distintas realidades.

\section{Para não findar: outras considerações sobre a saúde da família do campo}

De maneira geral, as atividades desenvolvidas pelas equipes de saúde da APS estão no elenco do que é preconizado pela PNAB (BRASIL, 2017), que não destaca aspectos relativos às especificidades da população do campo. No item que apresenta a atribuição de cada profissional, é possível constatar que não há menção às atividades em conformidade com as realidades rurais. Nesse documento, no item que trata da infraestrutura, ambiência e funcionamento da Atenção Primária, consta apenas que as Unidades Básicas de Saúde poderão ter pontos de apoio para o atendimento de populaçôes dispersas (rurais, ribeirinhas, assentamentos, áreas pantaneiras etc.).

Apesar de a maioria dos profissionais reconhecer a dificuldade em incluir atividades de prevenção ao adoecimento e promoção da saúde no cotidiano do serviço, em alguns discursos, fica evidente que os usuários, às vezes, associam a USF à doença e só buscam os cuidados da equipe quando já têm alguma queixa, não 
buscando de maneira preventiva e de promoção da saúde. Portanto, percebe-se uma retroalimentação entre oferta e demanda. Enquanto o serviço oferece mais ações curativas, a comunidade entende que esse é o seu papel e procura por esse tipo de cuidado, e, ao fazer isso, demanda essa intervenção por parte da equipe, e ambos seguem sem romper com essa lógica.

Diante disso, torna-se imprescindível o incentivo à educação permanente acerca dos modos de vida dos povos do campo, incentivo à prática interdisciplinar, garantia de transporte às equipes, fomento à organização nos assentamentos em torno da valorização das práticas tradicionais, planejamento e avaliação envolvendo equipes, setor saúde do MST e famílias visando à participação coletiva na construção do cuidado e efetivação da APS.

Desse modo, ampliam-se as chances de serem apreendidas as questóes estruturais do processo saúde-adoecimento, favorecendo a construção de práticas de saúde mais resolutivas, integrais e comprometidas com a realidade socioeconômica, cultural e sanitária dos assentamentos da Reforma Agrária. ${ }^{2}$

\section{Referências}

BRASIL. Ministério da Saúde. Secretaria de Gestão Estratégica e Participativa. Política Nacional de Saúde Integral das Populaçóes do Campo e da Floresta. Brasília: Ministério da Saúde, 2013. . Ministério da Saúde. Departamento de Atenção Básica. Secretaria de Atenção à Saúde. Informação e Gestão da Atenção Básica. Brasília: Ministério da Saúde, 2017a.

. Ministério da Saúde. Política Nacional de Atenção Básica Operacionalização. Portaria $n^{\circ} 2.436$, de 21 de setembro de 2017. Aprova a Política Nacional de Atenção Básica, estabelecendo a revisão de diretrizes para a organização da Atenção Básica, no âmbito do Sistema Único de Saúde (SUS). Brasília: Ministério da Saúde, 2017.

CALDART, R. S. Pedagogia do Movimento Sem Terra. 4. ed. São Paulo: Expressão Popular, 2012. CARNEIRO, F. F. et al. Teias de um Observatório para a saúde das populaçóes do campo, da floresta e das águas no Brasil. Rev Tempus, actas de saúde colet, Brasília, v. 8, n. 2, p. 275-293, jun. 2014.

CÓRDOVA, T. A. B.; RIBAS, C. E. D. C.; WOSNY, A. M. A assistência à saúde dos Sem-Terra: o caso do assentamento Butiá, Santa Catarina. Brasil. Rev. Saúde \& Transf. Soc. Florianópolis, v. 1, n. 2, p. 67-78, 2011. ISSN 2178-7085.

FERNANDES, B. M. O MST e as Reformas Agrárias do Brasil. Boletim DATALUTA. Artigo do mês. Dez. 2008. 
GARNELO, L. et al. Acesso e cobertura da Atenção Primária à Saúde para populações rurais e urbanas na região norte do Brasil. Rev. Saúde Debate, Rio de Janeiro, v. 42, número especial 1, p. 81-99, set. 2018.

INSTITUTO NACIONAL DE COLONIZAÇÃO E REFORMA AGRÁRIA. Incra nos Estados: informaçóes gerais sobre os assentamentos da Reforma Agrária. 2017. Disponível em: http://painel.incra.gov.br/sistemas/index.php. Acesso em: abr. 2017.

MALTA, D. C. et al. A Cobertura da Estratégia de Saúde da Família (ESF) no Brasil, segundo a Pesquisa Nacional de Saúde, 2013. Ciência \& Saúde Coletiva, v. 21, n. 2, p. 327-338, 2016.

MOVIMENTO DOS TRABALHADORES RURAIS SEM TERRA. Nossa história. 2014.

Disponível em: <www.mst.org.br/nossahistoria>. Acesso em: 14 abr. 2017.

. Secretaria Nacional. Relatos de experiência em saúde. Brasília: MST, 2005.

NANDO, N. M. et al. Declaração de Brasília. O conceito de rural e o cuidado à saúde. Rev. Bras. Med. Fam. comunidade, Florianópolis, v. 6, n. 19, p. 142-4, abr.-jun. 2011.

STARFIELD, B. Atenção Primária: equilíbrio entre necessidades de saúde, serviços e tecnologia. Brasília: UNESCO: Ministério da Saúde, 2002. 760 p.

STEDILE, J. P. A questão agrária no Brasil: o debate na esquerda - 1960-1980. 2. ed. São Paulo: Expressão Popular, 2012. 320 p.

TARGA, L. V. et al. Declaração de Gramado pela Saúde Rural nos países em desenvolvimento. Rev. Bras. Med. Fam. Comunidade, Rio de Janeiro, v. 9, n. 32, p. 292-294, jul.-set. 2014.

VENTURA, M. M. O estudo de caso como modalidade de pesquisa. Pedagogia Médica. Rev SOCERJ, v. 20, n. 5, p. 383-386, 2007.

YIN, R. K. Estudo de caso: planejamento e métodos. 2. ed. Trad. Daniel Grassi. Porto Alegre: Bookman, 2001.

\section{Notas}

${ }^{1}$ Distribuição das máquinas de costura nos cômodos das casas, dando origem a uma espécie de "fábrica", onde são desenvolvidas algumas das etapas da produção têxtil, como inclusão de zíper, bolsos, botóes nas peças de roupa para comercialização.

${ }^{2}$ A. C. M. T. V Dantas trabalhou na concepção, redação e revisão final do artigo. P. L. Martelli colaborou na concepção, revisão final e aprovação do artigo. P. C. Albuquerque, na concepção, redação e revisão final. R. M. P. F. de Sá, no delineamento metodológico, redação e revisão final. 


\section{Abstract}

Reports and reflections on primary health care in Agrarian Reform settlements

This case study aimed to analyze the health care of families settled in the countryside of Pernambuco state, Brazil, through participant observation, individual interviews with health professionals and representative of the Landless Workers Movement (MST), focus groups with families from two settlements and field diary. Health practices were related to the popular care through the use of medicinal plants, preventive actions, such as vaccination, childcare, monitoring of hypertensive and diabetic patients, water treatment and waste destination. We identified that socioeconomic, cultural and educational factors had a negative impact on health conditions, while the training of professionals and the resolving capacity of Primary Care limited the supply of actions. Although health practices were in accordance with the National Primary Care Policy, there were gaps between making technical health and making health popular. The actions carried out by the Movement were highlighted, such as the diagnosis of health status and planning, based on popular education. The health needs presented by the families demanded of the teams specific skills and abilities for the integral health care implied with the socioeconomic, cultural and sanitary reality of the Agrarian Reform settlements.

> Keywords: health policy; primary care; family health; rural health. 